\title{
Downtown Pedestrian mall as a Strategy to Enhance the Egyptian Street Life
}

\author{
Nesma, A, Fadda ${ }^{1}$, Sherine, M, Wahba ${ }^{2}$, Basil, A, Kamel ${ }^{3}$ and Aly, K, \\ Kandil $^{4}$,
}

\begin{abstract}
:
The persistent deterioration of the street life in Egypt became an evident in overcrowded cities such as Cairo. This is well identified in mixed use/commercial streets in general, and in downtown's ones in particular. In fact, these streets are functioning as corridors for vehicular movement, rather than places for people's activities, that resulted in a street life deterioration; physically, in terms of traffic conflict due to the urban growth that led to vehicle invasion, and socially in terms of people's use limitation to streets due to social mobility and public realm privatization that led to indoor shopping mall invasion that has contributed to emptying out the commercial activities from downtown's streets. The paper suggests the applicability of pedestrian malls in city centers as a strategy to enhance the quality of the street life. Hence, this research investigates the pedestrian malls as an application of commercial street design that balances the dual functions of the street as a movement corridor as well as a place for activities. Firstly, it attempts to explain and categorize the street life deterioration in Egypt. Secondly, to identify the benefits of the pedestrian mall as a solution. Finally, to analyze and evaluate the level of success of one of the newly implemented pedestrian malls in Cairo's downtown and to compare it with an international case study street. The findings of the research set some principles for selecting streets that have potential to be converted into successful pedestrian malls that could contribute to enhancing the Egyptian street life.
\end{abstract}

Keywords: Street Life - Walkability - Pedestrian Mall - Cairo's Downtown Mixed use/Commercial

Streets.

\footnotetext{
${ }^{1}$ Assistant Lecturer of Architecture, Faculty of Engineering, Cairo University.

${ }^{2}$ Professor of Architecture, Faculty of Engineering, Cairo University.

${ }^{3}$ Professor of Architecture, School of Science and Engineering, The American University in Cairo.

${ }^{4}$ Assistant Professor of Architecture, Faculty of Engineering, Cairo University.
} 


\section{Introduction}

This research investigates the applicability of pedestrian malls as a downtown strategy to enhance the quality of street life. Firstly, it attempts to address the physical and social deterioration that resulted in many problems and challenges facing people on Cairo's downtown mixed use/commercial streets; physically as corridors for walking, and socially as places for shopping, social interaction and other related activities. Secondly, to identify the benefits of pedestrian malls in relation to walkability and street activities. Finally, to evaluate the interventions in Cairo's downtown mixed use/commercial streets. The paper focuses on the pedestrianization of Al-Sharyfain street as a pilot case study; and critically provides a comparative analysis between it and Buchanan street at Glasgow, Scotland as an international case study street. The main approach of the investigation capitalizes in dealing with the downtown commercial streets as both movement corridors and places for people's activities. The concept of dealing with streets as places for people is not new and has already been addressed by many theorists and urban planners since in Jacobs's first publications on the importance of streets and sidewalks as the main public places within cities [1]. When converting a commercial street into a pedestrian mall, vehicular access is banned in order to enhance the outdoor environment for pedestrians. Pedestrian traffic can then be multiplied and shoppers are now coming back to shop safely and comfortably on the street. It is theoretically and practically confirmed that street pedestrianization increases sales and retail rents [2].

\section{Importance of the Street}

Throughout history, a cross many cultures and times, the street has held vast social, commercial, and political functions as a powerful symbol of the public realm [3]. Studies indicated that cities that have organized streets and public spaces are more livable and productive. Streets are the places used by people on daily basis, from which they can access their homes, do their business, socialize and meet others. Streets are the point at which people connect to the rest of the community, the region and even more. They are the places that visitors first recognize when arriving at new communities [4]. They have a greater function than being intersected corridors that support vehicular mobility. Rather, streets are public places that help enhancing social interaction, active living, and community identity [5]. Jacobs (1961) stated that streets are the structural organs of cities, and they have to be significant places for people and do more than allowing them to safely and comfortably walk or cycle through [1]. In order for streets to be significant places, they should support people to perform a variety of activities such as walking, socializing, and experiencing the character and identity of a particular area [3]. Since ancient times, streets have played a critical role in cities, contributing to the connection of spaces, people and goods, and thereby enhancing commerce, social interaction and mobility [6]. However, nowadays when planning streets, the multiple functions of the street are poorly integrated. This traditional representation of the street as a corridor for vehicular traffic has resulted in using the street only 
physically through its movement function, ignoring its social function as a place for people's activities. Streets have therefore lost their multi-functionality as public spaces [7]. However, a recent UN-Habitat report shows that "those cities that have failed to integrate the multi-functionality of streets tend to have lesser infrastructure development, lower productivity and a poorer quality of life" [8]. Today, many people all over the world are reclaiming their streets as public places. Streets in return started to be re planned to cope with the full use by people through transforming street space into public place where people can safely walk, stroll, cycle, talk, socialize, slow down, relax, do shopping. Lynch (1960), stated that streets have an essential role in defining the city structurally, through facilitating places for social and economic activities [9]. In respect to the vital role of streets in the city, Jacobs (1961), described streets and their sidewalks as the most critical components of the public realm. There are various functions and activities occur along the streets simultaneously [1]. Speck (2010), confirmed that no amount of 'pedestrian facilities' have ever, or could ever, by themselves make a place successful and walkable. To be favored, a walk has to respect four main dimensions: it must be useful, safe, comfortable and interesting [10]. Jacobs (1961), Appleyard (1981), Anderson (1986), Moudon (1991), and Jacobs (1993) have emphasized how streets and sidewalks can contribute to social and community interaction. Their works helped reuse the street as an essential public place rather than a channel dedicated only for vehicular traffic [11-14].

\section{The Deterioration of Street Life in Egypt}

Generally, studies have shown obviously that as vehicular traffic on a street increases, the social life on it declines. The noise, unsafe environment, and pollution slowly get people away from the street [15]. During the second half of the 20th century, the car ownership has rapidly grown. Its effect on the main street is proved not only through traffic conflict, street re-design in order to cope with the increased traffic and parking, but also through the deterioration of the social and economic functions of the street. Commercial development, economic, social and leisure activities have all been affected by the transformation in the urban environment that vehicular use has supported. This is the exact case of Egyptian streets; there is an obvious limitation of people's use of the streets, people walk in downtown because they have to, not because they want to.

Moreover, transformations in Egyptian planning policies since the 1990s allowed for an expansion of suburban developments that included hypermarkets, leisure parks and indoor shopping malls. This shift in policies was related to public realm privatization during Nasser's period, guided by international financial organizations that lead to further economy privatization. Nevertheless, by the time this policy was able to affect developments, many downtown's commercial streets were already suffering competition from, and loss of customers to, these alternative commercial environments. While Egyptians may have adapted to this new lifestyle, many consolidated urban environments have experienced urban deterioration [16]. 


\subsection{Physical Deterioration: Traffic Conflict}

Referring to Egypt, it is ranked the 115th country in the individual's level of happiness and quality of life, which is a very low global level, where it is assumed that the shortage in open spaces provision is one of the causes that negatively impacts the people's level of happiness and overall quality of life [17]. Particularly in Cairo, when talking about public spaces, streets, especially mixed use/commercial ones, have an essential role due to the shortage in other types of urban spaces. However, currently, one cannot find many examples of livable streets that are pedestrian friendly and accommodating to all street users. Although many people rely on walking and public transportation for their daily travel, with the exponential increase in vehicle numbers and use, limited attention has been given to pedestrian and public transportation facilities. Egyptian streets offer a limited and unsafe environment for pedestrians to satisfy their needs in walking or socializing [18]. Although economic vitality of streets is a healthy feature of the city where interaction among people with different socio-economic backgrounds takes place; however, it should not be exceeding other aspects. The same case is for vehicle invasion in the streets of Cairo, either in traffic or encroaching on sidewalks for parking, leaving a limited space for people for their activities, or even to have safe crossings from one point to another. the number of accidents is likely to increase. Furthermore, the challenges faced by developing countries such as Egypt are often different from those faced by developed countries; where in Egypt for instant, there is a large number of two wheelers, three wheelers, bicyclists, and pedestrians sharing the same road space with vehicles, buses, and trucks that led to a serious traffic conflict.

\subsection{Social Deterioration: Limitation of people's use}

Cairo is a Multi-Layered Cultures City which has formed different urban tissues during its lifetime. The architecture and urban fabric of Cairo reflect these various eras of its history [19]. Urban characters which have changed over the time from historical Islamic to contemporary planned, have a great influence on shopping activities. For many Egyptians with different social and income levels, shopping has never lost its value during the process of urban growth and development both in indoor and outdoor commercial environments. Shopping is considered to be an everyday physical activity and a social practice as well as consumption. Therefore, the commercial environments being as pedestrian places should deal with both social and physical as well as environmental aspects. In Egypt, like any other country around the world people go for shopping basically for two reasons; first, they are driven by consumerist fantasies and the second, is to find a common ground for sociability in the community [20]. Along a heavy traffic commercial street, outdoor shopping may not be as interesting and safe as indoor one, because of the serious air pollution, poor environment and hazards caused by the vehicular traffic [21]. Indoor shopping malls provide an isolated, safe, secured and comfortable commercial environment, especially in suburbs and they have begun to function as city centers [19]. Changes in Egyptian planning policies in the 1990s 
permitted an expansion of suburban developments that shopping malls. This shift in policies was related to the structural adjustment and public realm privatization during Nasser's period, guided by international financial organizations that lead to further economy privatization and liberalization [22]. There is a clear multiplication of shopping malls, however the malls are successful, and despite of acute economic crisis, Cairo is witnessing a boom in the construction of shopping malls. Through recent years, the growing number of new Egyptian indoor shopping malls specially in new suburbs have contributed to emptying out retail activities from downtown and many original planned commercial streets. Moreover, social mobility in Egypt was the primary dominant force that contributed to the new Egyptian lifestyle, that was driven from some political ideologies [23]. After 1952 revolution followed by the foreigner community departure from downtown districts; they suffered from social deterioration. Downtown commercial streets remained the center for the elites and the hub for retail and cultural activities until the establishment of the Republic of Egypt in 1952, which created a great shift in the social fabric of its residents [24]. Afterwards, downtown started gradually to be transformed into a destination for the middle and low income groups. Consequently, this caused a transformation in the identity of downtown over the past years from an elite and unique place to one that average Egyptians claim as their own, with the growing numbers of affordable goods through small shops and street vendors, and traditional cafes [23]. Many stores changed their merchandise to cater to their new clientele, and the stores gradually changed in character over the coming decades. Consequently, people's use of these streets was limited and streets were emerging as parking spaces rather than places for people. Nowadays, shoppers in Egyptian mixed use/commercial streets are suffering from many problems that can be divided into three main categories; corridor related problems, place related problems and place/corridor related problems. The three categories are explained in diagram 1.

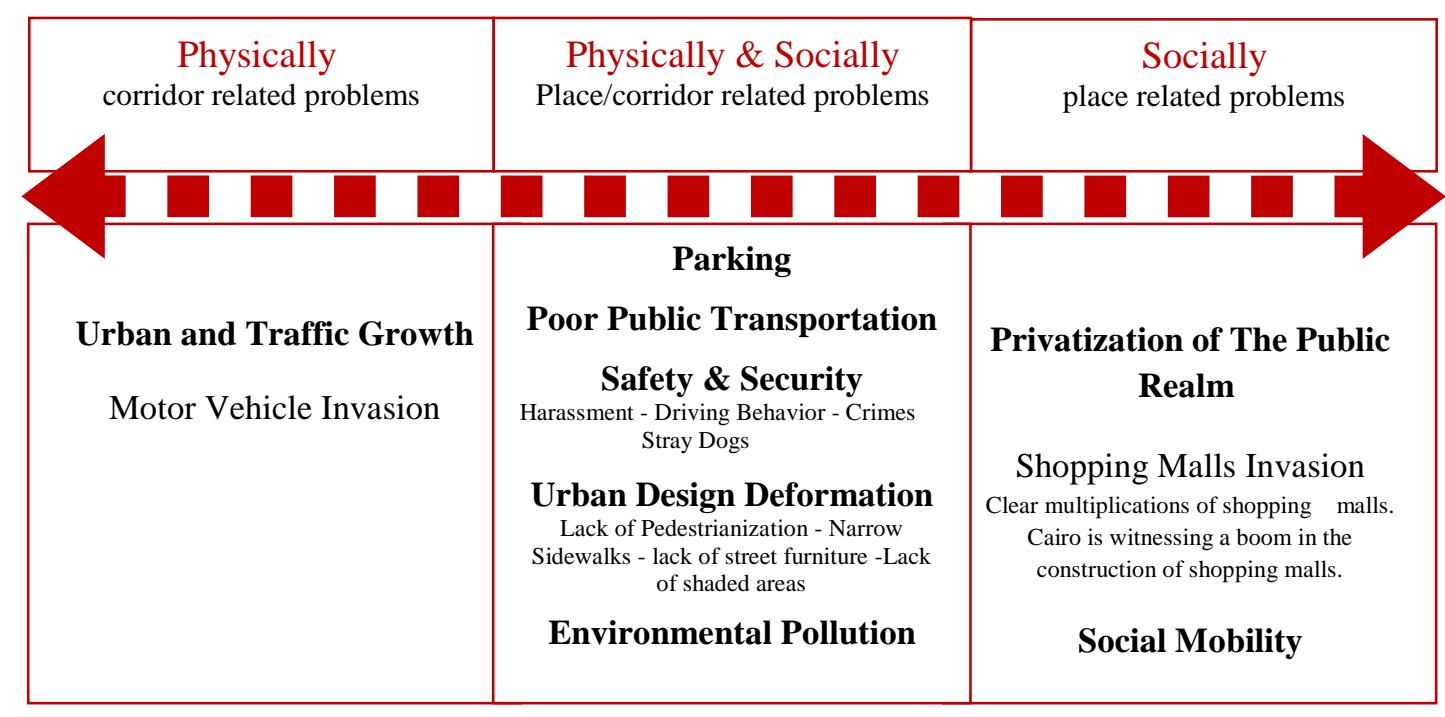

Diagram 1: The Main Reasons for Egyptian Street Life Deterioration, Researchers. 


\section{Pedestrian Mall as a Solution}

A pedestrian mall is defined as a number of continuous blocks along a commercial/ shopping street, that is used by people on foot. Pedestrian malls are one of the most essential components of urban spaces [25]. Pedestrian malls generally have a significant role in the regeneration of city centers, which are declining as a result of shopping malls built in suburban areas. Studies indicated that, in addition to contributing to downtown regeneration, pedestrian malls in general help improving the urban image, contribute to the public space character and have positive impact on enhancing the quality of urban life. In order for a pedestrian mall to enliven the city center, the area needs to be supported with vehicle parking and high-quality transportation systems.

\subsection{The Evolution of Pedestrian Malls}

The Agora, Greek market place was the beginning of the developmental process of urban public spaces, that had commerce and government facilities. It was people- oriented before the invention of vehicles. Republican Forum was the commercial and governmental center of Rome that worked as a marketplace too. In the medieval era, commercial activities raised the need for market places in larger spaces due to the population growth. Furthermore, when these kinds of larger buildings increased in time, the planners began to group buildings around squares to shape plazas. Therefore, religious ceremonies, governmental events, and theatrical productions were placed in plazas. For instance, Piazza del Campo in Siena, Italy constructed between 1288 and 1413. In the seventeenth century, plazas were more enclosed and isolated spaces than in the eighteenth century, whereas spaces were more opened. After the industrial revolution, vehicular movement became dominant causing a negative effect that reached its maximum in the1960s. In the last half of the nineteenth century, Paris Boulevards played an important role in the development of pedestrian malls. In addition, in West Germany, there was a roar in the implementation of pedestrian malls due to the traffic congestion in narrow shopping streets, that resulted in to 800 pedestrian malls by the end of 1980s [26]. In the early twentieth century, it was very common to close narrow medieval commercial streets to vehicular traffic. However, the concept changed in the mid-twentieth century, especially in the city centers; pedestrian traffic was narrowed because of the growing amount of vehicles [27]. In 1923, Britain discovered the pedestrianization of commercial streets, whereas high streets were pedestrianized in the late 1960's. In those years, Germany affects America in terms of a traffic-free concept. In 1959, Kalamazoo, Michigan, was the first downtown pedestrian mall to be implemented in the United States. Nevertheless, few numbers of new pedestrian malls have been built since 1980s. After World War II, pedestrian malls have been developed. The idea of the marketplace with its mixed uses, activities, and amenities relates back to the ancient Greek Agora where the initiative concept for pedestrian mall developments began to exist, and continues to support the same human needs today [26]. Figure 2 illustrates the evolution of pedestrian malls. 


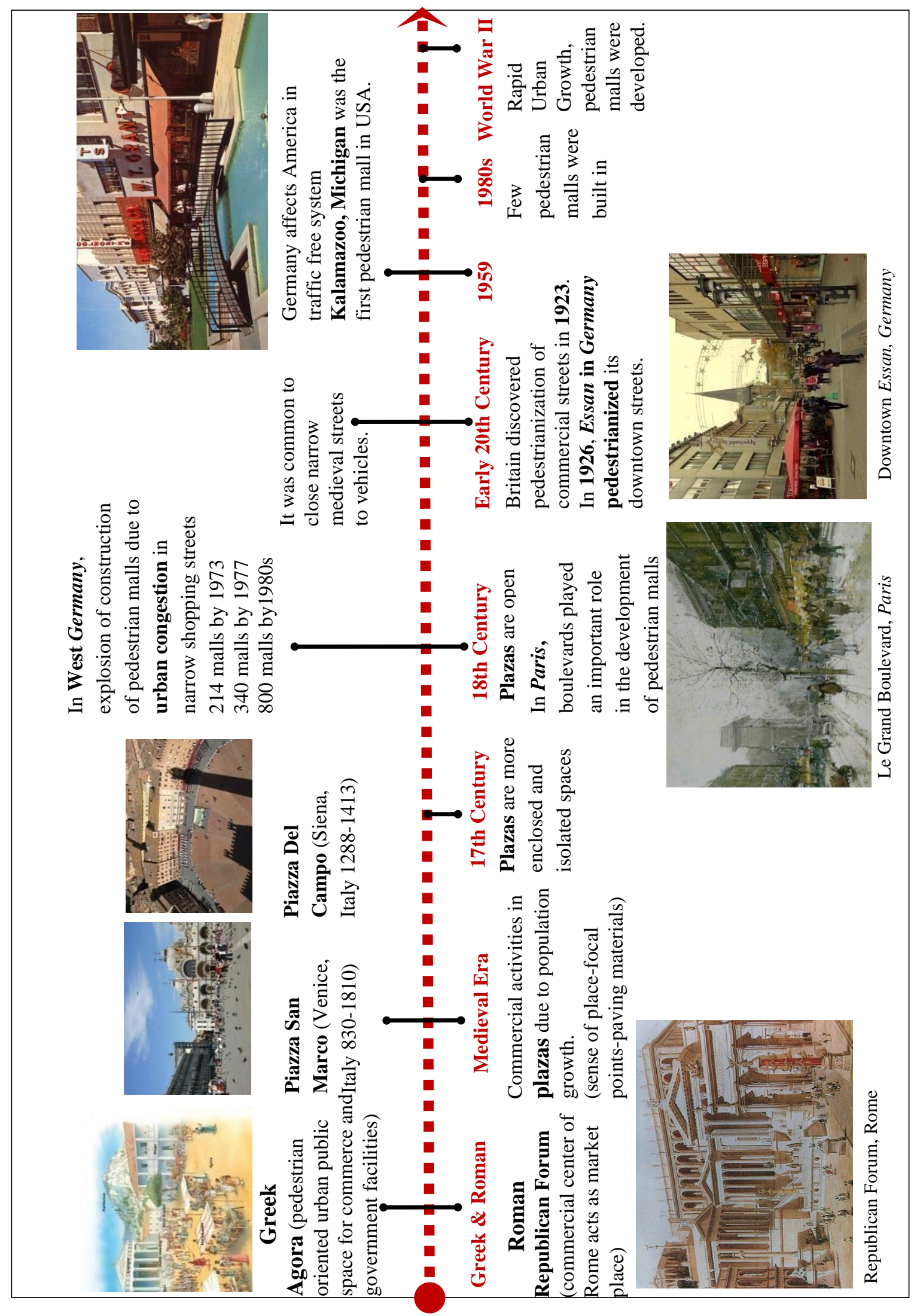

Figure 2: The Evolution of Pedestrian Malls, Researchers. 


\subsection{Types and Benefits of Pedestrian Malls}

There are three main types of pedestrian malls. They present different design concepts; first, full mall, sometimes named as traditional pedestrian mall, where pedestrians have the complete priority over vehicular traffic. It is created by closing a street for vehicular traffic and improving the pedestrian street with new paving, trees, lightings and other street furniture. Vehicular access is totally banned except for emergency vehicles, when necessary, as well as service and supply vehicles that are restricted to either limited delivery hours or entrances in back streets. The full mall help providing visual continuity, a special character, and enhance the image and sense of place for the downtown. Second, Transit mall that is the most common type of pedestrian malls. Transit mall permits only public transit such as buses, or light rail on an existing main commercial street. It aims at linking activities along its route involving retail, office, hotel, entertainment, and housing. Moreover, transit mall helps creating a unity in terms of a city image. Rubenstein, 1992 states that "the transit way acts as a retail spine or corridor through the downtown" [26]. On street parking is prohibited, walkways are widened, and specially designed streetscape treatment is provided to create a unique image for the downtown [28]. Third, Semi mall or shared mall, where there is no restriction to vehicular access. However, vehicles are slowed down through the use of traffic calming measures [29]. The street in this regard, is being shared by all users. Usually a shared mall is being used to increase the level of activities and make the street more livable [25]. Shared malls involve one of two approaches. First, curbs are removed, allowing all users to share the same large space. Second, sidewalks are widened, speed limits are decreased. Generally, with the competition of indoor shopping malls, rental level of shops on commercial streets is decreasing. However, by converting them into pedestrian malls, many benefits could be accomplished [30]. Table 1 is summarizing the benefits of pedestrian malls [25-30-31-32].

Table 1: Benefits of Pedestrian Malls

\begin{tabular}{|l|l|l|l|l|}
\hline \multicolumn{1}{|c|}{ Urban Benefits } & Health Benefits & Social Benefits & Economic Benefits & \multicolumn{1}{|c|}{$\begin{array}{c}\text { Environmental } \\
\text { Benefits }\end{array}$} \\
\hline $\begin{array}{l}\text { Reducing vehicle } \\
\text { use, congestion \& } \\
\text { parking. }\end{array}$ & $\begin{array}{l}\text { Public health } \\
\text { development. }\end{array}$ & $\begin{array}{l}\text { Enhancing } \\
\text { social } \\
\text { interaction. }\end{array}$ & $\begin{array}{l}\text { Improving } \\
\text { economic } \\
\text { productivities. }\end{array}$ & $\begin{array}{l}\text { Reducing air } \\
\text { pollution. }\end{array}$ \\
$\begin{array}{l}\text { Improving } \\
\text { mobility \& } \\
\text { accessibility. }\end{array}$ & $\begin{array}{l}\text { Physical Activity } \\
\text { enhancement. }\end{array}$ & $\begin{array}{l}\text { Increasing sense } \\
\text { of security and } \\
\text { safety. }\end{array}$ & $\begin{array}{l}\text { High pedestrian } \\
\text { traffic. }\end{array}$ & $\begin{array}{l}\text { Reducing noise. } \\
\text { Greenery and } \\
\text { plantation. }\end{array}$ \\
$\begin{array}{l}\text { Heritage } \\
\text { preservation and } \\
\text { urban renewal. }\end{array}$ & $\begin{array}{l}\text { Enhancing } \\
\text { community } \\
\text { livability. }\end{array}$ & $\begin{array}{l}\text { \& retail rents. } \\
\text { High } \\
\text { employment } \\
\text { ratio. }\end{array}$ & $\begin{array}{l}\text { Environmentally/fri } \\
\text { endly } \\
\text { transportation. }\end{array}$ \\
\hline
\end{tabular}

\section{Case Study Streets}

Because downtown pedestrian commercial streets are diverse, composite, and have not been intensively studied in an integrated 'place-corridor' concept, a case study 
approach was used in order to meet the objectives of this research. Two pedestrian malls, namely as Al-Sharifayin and Buchanan were analyzed and evaluated to figure out the level of success of each one.

\subsection{Buchanan Street, Downtown Glasgow, Scotland}

Glasgow is considered to be Scotland's largest city, it is widely known as being the UK's best retail centre and a European leading fashion destination in addition to London. Buchanan street is the main shopping street in Glasgow as well as Scotland. It is recognized as the best place for people gathering and as significant part of the fabric of Glasgow's ancient city center that occupied with elegant shopping centers, restaurants and many cultural highlights such as the Glasgow Royal Concert Hall. Buchanan street functions as Glasgow's retail anchor and best place for social interaction and activities. It attracts 30,000000 pedestrians per year [33]. Figure 3 provides for the location and accessibility of Buchanan street as well as the nearby landmarks.

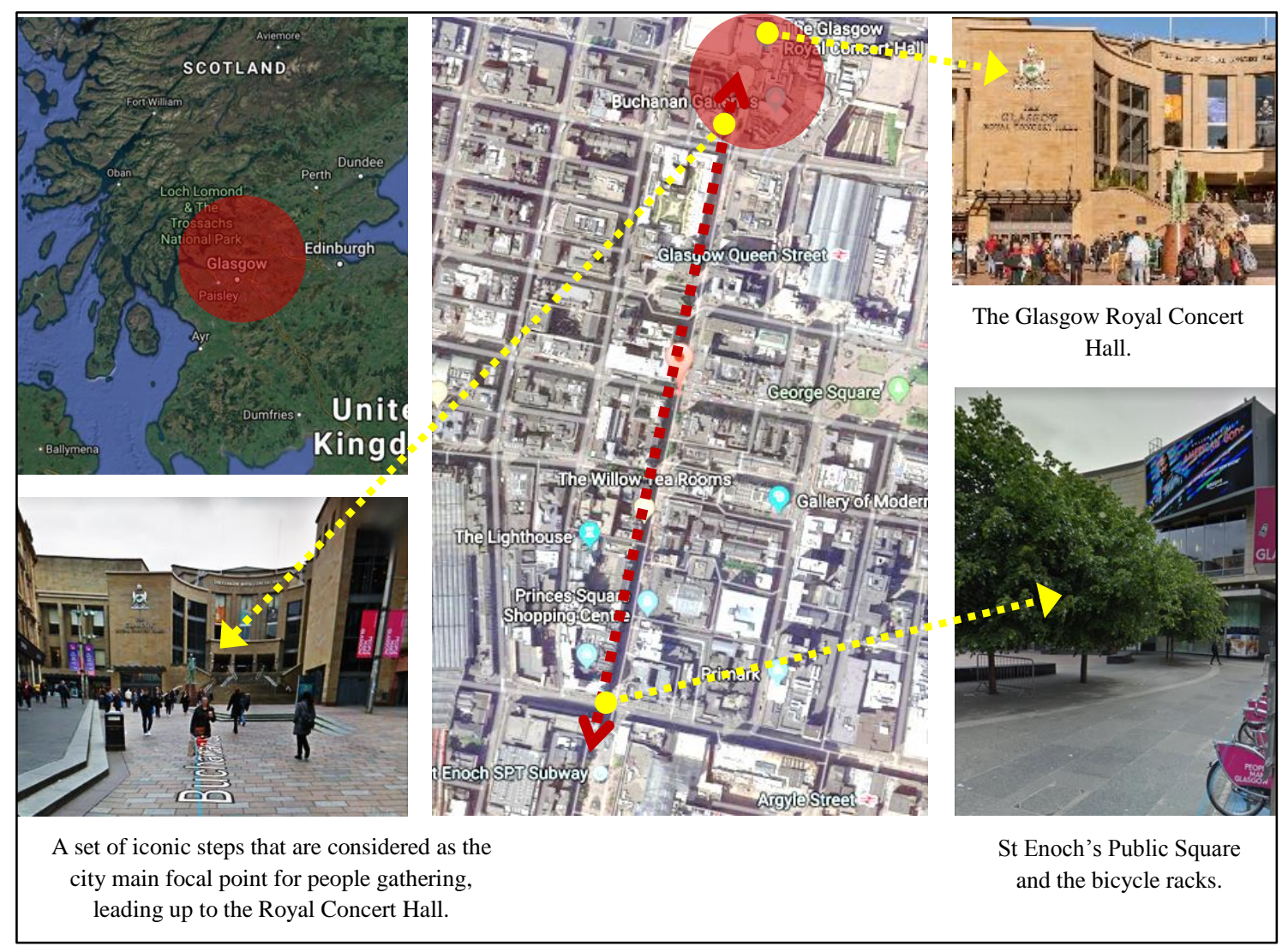

Figure 3: Maps and Shots showing Location and Accessibility of Buchanan Street, Downtown Glasgow, Scotland, Google maps, 2019.

\subsubsection{Urban Morphology and Historical Background}

Buchanan street is Scotland's principal shopping street, best place for people gathering and significant part of the fabric of Glasgow's ancient city center that occupied with elegant shopping centers, restaurants and many cultural highlights such as the Glasgow 
Royal Concert Hall. It was named after Andrew Buchanan, a Tobacco Lord, who predicted that Glasgow would spread westward. The street runs north-south starting with a set of iconic steps that are considered as the city main focal point for people gathering, leading up to the Royal Concert Hall. It ends south at St Enoch's Square. Buchanan street is the main shopping destination in the city, with fashion boutiques and several stylish retail centers. Buchanan street was first pedestrianized in 1978, and then the upgrading process of its public realm was completed in 2000 . It is $1 \mathrm{~km}$ long and over 20 meters wide. In 2003 it was ranked as Scotland's favorite street and was awarded a Congress for New Urbanism award for excellence in 2004.

\subsubsection{Land Uses \& Street Activities}

Buchanan street is the main shopping destination in the city, with fashion boutiques and several stylish retail centers. Along the street, it contains numerous shops, two shopping arcades, two major shopping centers, a museum and library, and a design center. Many restaurants and outdoor cafes are existing along Buchanan street. The street is wide enough to provide place for people's activities. There are regular displays of street theatre and a monthly farmers market. The iconic steps lead to the Royal Concert Hall are used as a main gathering place. The street functions as Glasgow's retail anchor and best place for people gathering and activities. It attracts 30,000000 pedestrians per year.

\subsubsection{Urban Interventions}

Buchanan street was first pedestrianized in 1987, then upgraded in 2000 as a result of an international urban competition. The upgrading process of Buchanan street included installation of new lightings, according to the golden section, provision of cafes on the east side with canopied enclosures, so that people could enjoy eating outdoor. Street furniture such as solid blocks of highly polished stone were installed to provide seating and new triple-tiered planters with attractive floral displays were added. Moreover, stainless steel litter bins, were provided as part of the street upgrading [33].

\subsection{Al-Sharyfain Street, Downtown Cairo, Egypt}

Al-Sharyfain street is recognized as the extension to Al-Shawarbi street. It is almost at the same axe, joining Qasr al-Nil street at the north and Mohamed Sabri Abou Alam street at the south, cutting through the heart of al-Bursa, or Stock Market Exchange district that was named for the Stock Exchange built in 1928 [34]. Besides the Stock Exchange, it includes many other financial institutions such as the Central Bank, the National Bank, Suez Canal Bank and the Arab African Bank. Moreover, it includes the National Radio station and a substantial number of mixed use buildings, established during 1920s to 1930s [35]. Figure 4 provides for the location and accessibility of $A l$ Sharyfain Street as well as the nearby landmarks. 


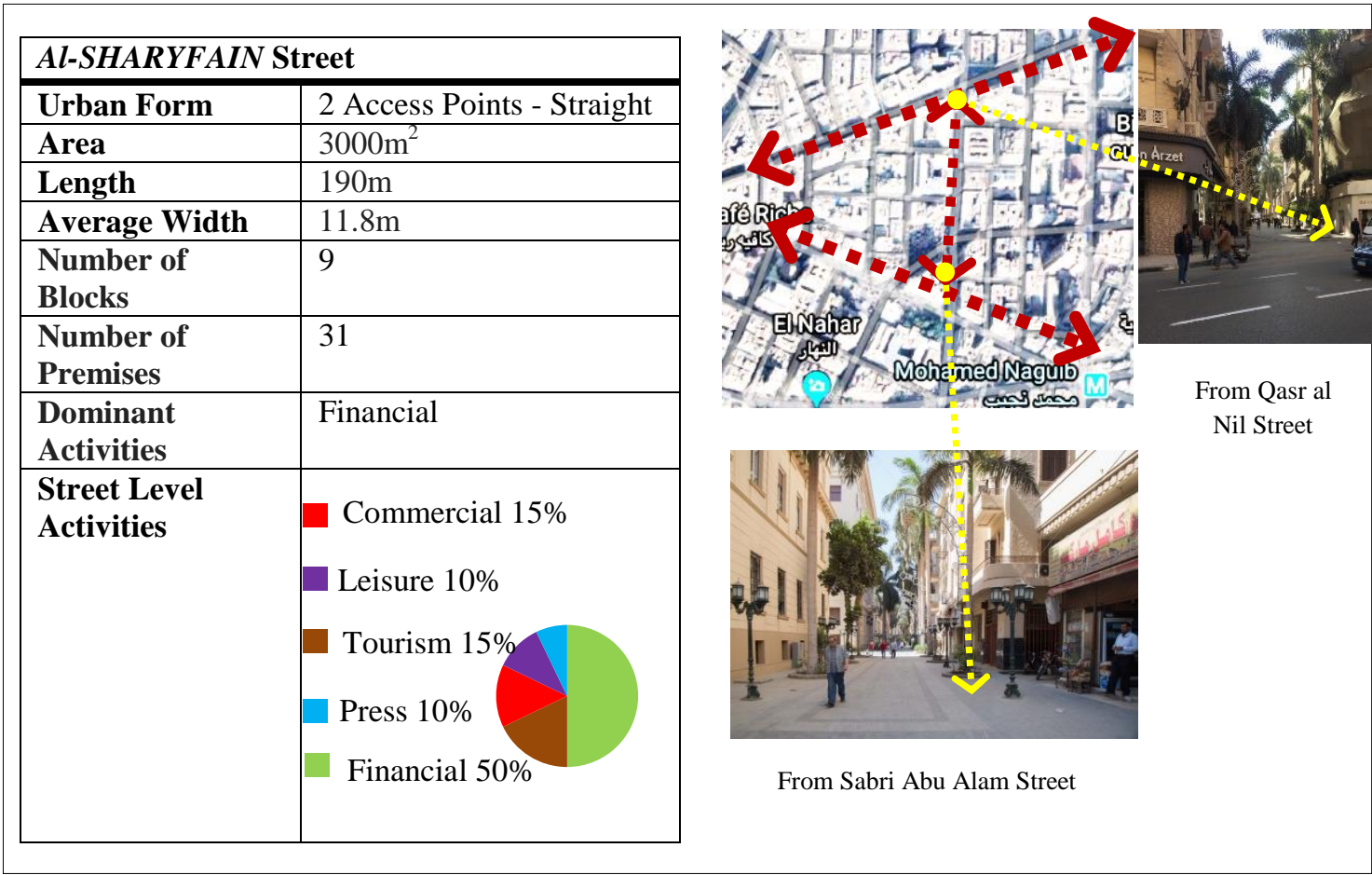

Figure 4: Basic Information, map and shots showing Location and

Accessibility of Al-Sharyfain Street, Downtown Cairo, Researchers, 2019.

\subsubsection{Urban Morphology and Historical Background}

Al-Sharyfain street is average 11.8 meters wide and 190 meters long, accommodating buildings with heights varying from $2-3$ floors and $4-5$ floors. The 12-meter width are not divided or assigned for different activities, however, street furniture (trees and lightings) are placed 1.5 meters away from the buildings. The urban space is determined by the ratio between the width of the street and the $3-4$ floors high buildings creating a significant urban enclosure that is naturally illuminated yet not fully shaded. It is considered to be the heart of Al-Bursa/ Stock Market Exchange district.

\subsubsection{Land Uses \& Street Activities}

Al-Sharyfain street is mostly occupied by various street services with 31 premises distributed along the street. The services are dominated by financial institutions and banks. Moreover, there are some stores, highlighted by Dalydress at the beginning of the street from Qasr Al Nil street. Tourism, press premises and art galleries are distributed along the street, as well as other shops that cater on the local community including a coiffeur and some supermarkets. The commercial services are coupled with leisure activities presented by Facebook and Al bursa cafés.

\subsubsection{Urban Interventions}

Al-Sharyfain pedestrianization project was carried out by Cairo Govern ate in the late 1990s during the renovations of the Stock Exchange. The street was struggling and overloaded by many cafes that caused a lot of chaos and affected the usability of it. 
The owners decided to close it to traffic and convert it into a pedestrian only street [36]. Furthermore, in 2018 the street was upgraded; the entire street was repaved with concrete tiles, lighting fixtures were installed, and palm trees were planted. It was reopened during the World Heritage Day. The street was redesigned in order to host cultural festivals and special events in weekends and holidays. However, many of its residents had many concerns against these events and consequently they were later canceled. It is worth mentioning that, after the upgrading process, the government created a board of trustees for the street maintenance and management.

\subsection{Analysis and Evaluation of the Case Study Streets}

The two case study streets were analyzed in terms of functioning as movement corridors, that could enhance walkability as well as places for activities that host everyday social and economic activities by people and encourage them to spend time on the streets, aiming at revealing their level of success. Regarding the local Egyptian case study street, the response of Al-Sharyfain street residents, visitors and shop owners to the pedestrianization project was assessed through a field survey; observations and interviews by researchers. Figures $5 \& 6$ provides main observations and analysis on both case study streets.

\subsubsection{As movement corridors:}

Buchanan street is hosting a high pedestrian traffic due to its strategically location in downtown Glasgow and due to its strong connections with the city many public transportation networks through subway, railway and bus stations that exist at either ends of the street as well as on the street itself. It acts as a main passageway that leads to the Royal Concert Hall that is heavily visited and provides tourist attraction. It attracts 30,000000 pedestrians per year.

Al-Sharyfain street was concluded to be used as a movement corridor for people. About $66 \%$ of the interview respondents mentioned that they move from place to place through it due to its strategically location as well as being safe, environmentally and physically comfort and visually interesting. However, people mentioned that there is no street furniture (benches) along the street.

\subsubsection{As places for activities and social interaction}

Buchanan street is considered to be the main shopping destination in Glasgow, with fashion boutiques, several stylish retail centers, restaurants and many cultural highlights. It acts as Glasgow's retail anchor and best place for people gathering and activities. The iconic steps that lead to the Royal Concert Hall are used as a main gathering place for people to socialize and interact.

Al-Sharyfain street was concluded to be used for accessing premises (35\%) more than being used as a place for activities $(11 \%)$ due to the lack of gathering spaces and sit table places (benches). 


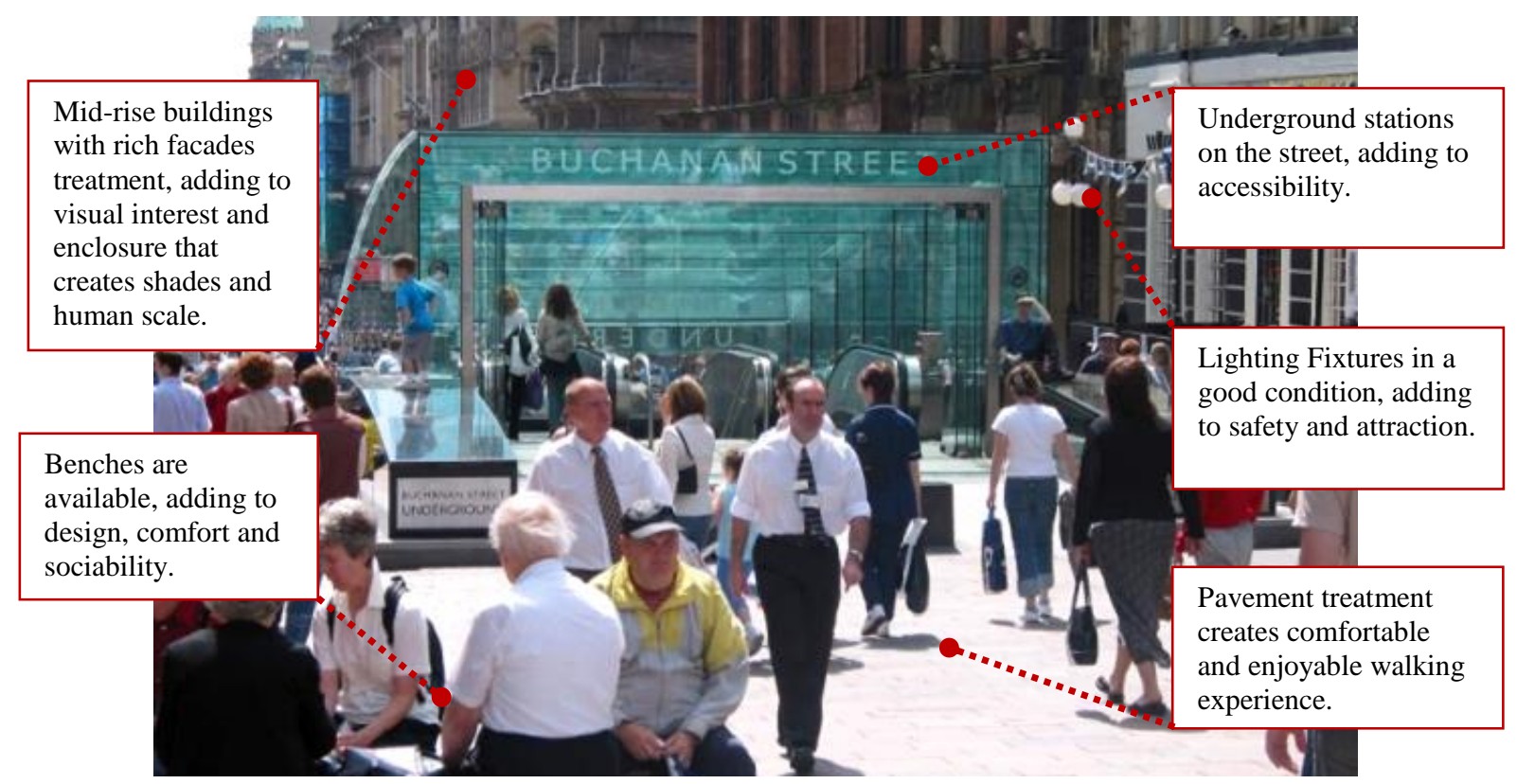

Figure 5: Main Analysis at Buchanman street: People walking and sitting, Rodriguez, L., 2011.

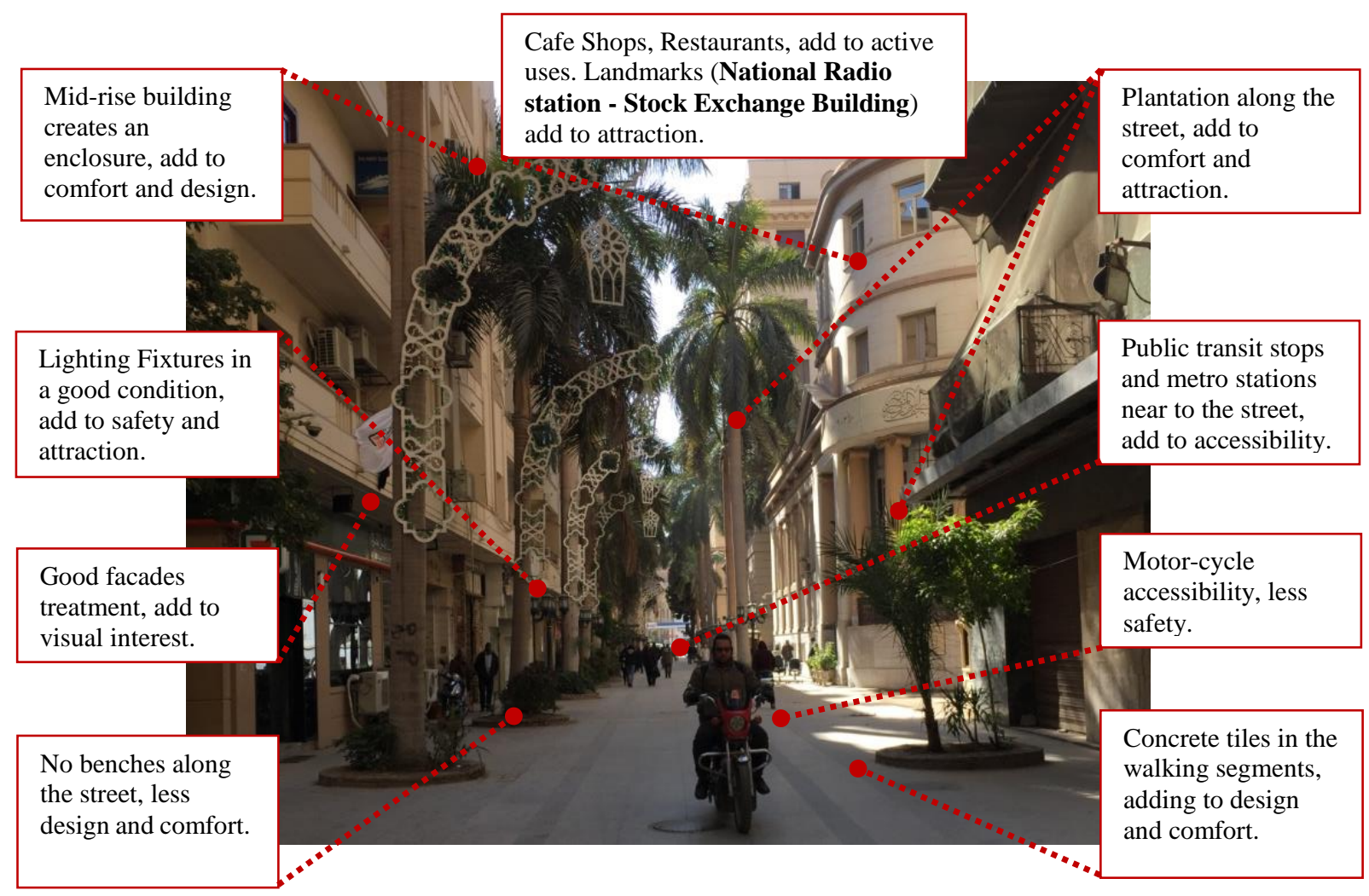

Figure 6: Main Observations and analysis at Al-Sharifayin street, Downtown Cairo, Researchers, 2019. 


\section{Concluding Remarks}

When downtown pedestrian malls are well planned, designed, physically as corridors and socially as places, managed and strategically connected to public transportation systems as well as pedestrian paths and bicycle routes, they can play an important role in improving the physical spatial quality of downtown commercial area. The key elements that contributed to the success of the international pedestrian mall, was the strategically location that cater for good accessibility and integration within the city. Regarding Egypt, planning strategies need to address the concept of commercial street pedestrianization. However, appropriate criteria should be adopted for the selection of the streets, while ongoing street management should take place afterwards. The research concluded proposed criteria to be considered by urban planners when selecting the streets that have potentials to be converted into pedestrian malls as following; 1) Location of the street in the city and its connections to the surrounding areas and activities in addition to its proximity to landmarks and heavily visited public premises. 2) Accessibility of the street and its connections with public transportation systems, pedestrian networks and bicycle routes. 3) Land uses and activities on the street. 4) Residential density on the street. 5) Safety and security on the street.

\section{References}

1. Jacobs, J. (1961),"The death and life of great American cities: The failure of modern town planning", Random House, USA.

2. Chung Y. (2011),"The impact of a pedestrianization scheme on retail rent: an empirical test in Hong Kong" JPMD, Vol. 4 Iss 3.

3. Mackenzie, A. (2015), "Reclaiming our streets as places: from transit routes to community roots", PPS.

4. Byrne, J. (2018), "Downtown Streetscape Manual - DRAFT - City of Edmonton".

5. City of Fort Myers. (2016), "COMPLETE STREETS Guidelines".

6. STREETS FOR PEOPLE COMPENDIUM. (2012), " STREET DESIGN GUIDING PRINCIPLES".

7. Rudfesky, B. (1969), "Streets for People; a primer for Americans", N.Y.

8. UN-HabitatReport. (2013), "STREETS AS PUBLIC SPACES AND DRIVERS FOR URBAN PROSPERTY", UN-Habitat, Nairobi.

9. Lynch, k. (1960), "The Image of the City", Massachusetts Institute of Technology and the President and Fellows of Harvard College Twentieth Printime.

10. Speck, J. (2012), "Walkable City: How Downtown Can Save America".

11. Appleyard, D. (1981), "Livable Streets". University of California Press, USA.

12. Anderson, S. (1986),"On Streets", MIT Press, USA.

13. Moudon, A. (1991), "Public Streets for Public Use", Columbia University Press.

14. Jacobs, A. B. (1993),"Great Streets", MIT Press, USA.

15. Nagati, O, Stryker, B. (2013), "Learning from Cairo: Global perspectives and future visions", http://clustercairo.org/cluster/publications, accessed 2019.

16. Tadamun (2016), "Urban Mobility: More than Just Building Roads", http://www.tadamun.info/2016/07/25/urban-mobility-just-building roads/?lang=en\#.WEDEu7J97IU, accessed 2019. 
17. Cairo Climate Talks (2012), "Greener Cairo: Visions and Realities", http://cairoclimatetalks.net/events/greener-cairo-visions-and-realitie, accessed 2019. 18. Stryker, B. \& Nagati, O. (2013), "Archiving the city in flux: Cairo's shifting urban landscape since the January 25th revolution", http://clustercairo.org/cluster/publications, accessed 2019.

19. Maarouf, N. \& El Alfy, A. (2012), "Towards Understanding Different Shopping Architectural Characters in Cairo". JASR, 8(2): 1303-1320.

20. Gottdiener, M. (1995), "Postmodern Semiotics: Material Culture and the Forms of Postmodern Life". Cambridge: Blackwell.

21. Bednar, M.J. (1989). "Interior Pedestrian Places". New York: Watson-Guptill P. 22. Abaza, M. (2006), "The Changing Consumer Cultures of Modern Egypt, Cairo's Urban Reshaping", Brill.

23. Amin, G. (1997), "Whatever happened to the Egyptians? A social history of Egypt 1945-1995", Cairo: Dar Al-Hilal.

24. Wanas, A. (2016), "Social Mobility and Green Open Urban Spaces with Reference to Cairo", GBER, Vol 10 Issue, 13-26.

25. Robertson, K. A. (1993), "Pedestrianization Strategies for Downtown Planners", Journal of the American Planning Association, 59, (3).

26. Rubenstein, Harvey M. (1992), "Pedestrian Malls, Streetscapes, and Urban Spaces", Canada: Avnone.

27. Lynch, K. (1990), "City Sense and City Design", Banerjee, T. and Soutworth M. London: MIT Press.

28. Evangelical Social Action Forum, "PEDESTRIANIZATION OF COMMERCIAL STREETS", Health Bridge, Canada, 2013.

29. Project for Public Spaces, "Street as Places: USING STREETS TO REBUILD COMMUNITIES", Project for Public Spaces, Inc. New York, 2008.

30. Oana-Elena BLAGA, "PEDESTRIAN ZONESAS IMPORTANT URBAN STRATEGIESIN REDEVELOPING THE COMMUNITY-CASE STUDY: ALBA IULIABOROUGH PARK" TRAS, No. 38 pp. 5-22, 2013.

31. Rodriguez, L., "Pedestrian Only Streets Make Communities More Livable", 2011.

32. Wright, L. (2004), " Reclaiming public space: The economic, environmental, and social impacts of Bogotá's transformation" Cities for People Conference, Walk21, Copenhagen, Denmark.

33. Murphy, N. (2004), "Great Public Spaces, Buchanan Street", PPS.

34. Hawas, S. (2002), "Khedivian Cairo - Identification and Documentation of Urban Architecture in downtown Cairo", The Arab Contractors Press: Cairo.

35. Attia, S., Shafik, Z., Halafawi, A., Khalil, H. (2016), "URBAN REGENERATION OF PUBLIC SPACE - AL-ALFI STREET - DOWNTOWN CAIRO", Proceedings of the $11^{\text {th }}$ International Conference on Urban Regeneration and Sustainability.

36. Cairo Downtown Passageways, http://passageways.clustermappinginitiative.org/en/passageways/e4-al-shawarbipassageway, accessed May 2019. 